\title{
Letter to the editor: applications of rib sparing technique in internal mammary vessels exposure of abdominal free flap breast reconstructions: a 12-year single-center experience of 215 cases
}

\author{
Stavros Samaras $^{1,2}$, Yoshie Sasaki ${ }^{1,3}$, Charles Malata $^{1,4}$ \\ ${ }^{1}$ Department of Plastic and Reconstructive Surgery, Addenbrooke's Hospital, Cambridge University Hospitals NHS Foundation Trust, Cambridge, \\ UK; ${ }^{2}$ Department of Plastic \& Reconstructive Surgery, 401 Military Hospital of Athens, Greece; ${ }^{3}$ Department of Plastic Surgery, Showa University \\ Hospital, Tokyo, Japan; ${ }^{4}$ Anglia Ruskin University School of Medicine, Cambridge and Chelmsford UK \\ Correspondence to: Professor Charles Malata, Department of Plastic \& Reconstructive Surgery, Box 186, Addenbrooke's University Hospital, \\ Cambridge University Hospitals NHS Foundation Trust, Cambridge CB2 2QQ, UK. Email: cmalata@hotmail.com. \\ Provenance and Peer Review: This article was commissioned by the Editorial Office, Gland Surgery. The article did not undergo external peer review.
}

Submitted Nov 25, 2019. Accepted for publication Dec 18, 2019.

doi: $10.21037 / g s .2019 .12 .21$

View this article at: http://dx.doi.org/10.21037/gs.2019.12.21

We read with great interest the article by Zhang and colleagues on the applications of rib sparing technique in internal mammary vessel (IMV) exposure for microvascular breast reconstruction (1). They report a retrospective single institutional study of 215 women who underwent 218 abdominal free flap breast reconstructions, 70 of them using rib-preserving exposure of the IMVs. They compared these with 102 flaps in which the costal cartilage was sacrificed. Their findings that rib sparing IMV exposure is a safe technique with a shorter surgery and hospital stay as well as lower complication rate compared to rib-sacrifice are consistent with our results from a study of the pertinent anatomy of the IMVs during total rib-sparing free flap breast reconstruction (2). Our comments are based on a prospectively collected database of such reconstructions performed by a single surgeon (CMM) using the total rib preservation technique of IMV exposure $(3,4)$.

Since the description of Parrett and his colleagues of the rib sparing IMV exposure in 2008 (5), this technique was promptly adopted and modified by the senior author and has since been used in all his breast reconstructions totaling more than 310 free flaps performed in 255 consecutive patients, predominantly using the 2 nd intercostal space. As detailed in our series, rib preserving IMV exposure is a safe technique with an overall flap success of $99.7 \%$ and an incredibly low re-exploration rate of $4.0 \%$ (2). However, contrary to the findings of Zhang et al. in which the rib sparing group of patients were taller and with a wider ICS suggesting a correlation between patient's height and ICS, in our experience there was no such correlation between intercostal distance and patient height, age, BMI or flap ischaemia time (6). We have also previously documented the beneficial effect of rib preservation IMV exposure on early postoperative pain (7). It is both noteworthy and incomprehensible that Zhang and colleagues make no mention of our work which detailed almost four times the number of rib-sparing cases as they report in their series of 70 such flaps (2). Though no doubt intentional, the title of their paper is also misleading as the rib-sparing technique only relates to 70 cases rather than 215 cases. Clarifying this in the title would have been most welcome and avoided any unintended ambiguity. Indeed a more informative title for their paper should have been "A comparison of rib sparing and rib-preserving IMV exposure in 215 abdominal free flap breast reconstructions: A 12-year single-center series/ experience".

Additionally we documented that, the second ICS at $20.6 \mathrm{~mm}( \pm 3.52)$ was consistently wider than the third $(14.0 \pm 4.35 \mathrm{~mm} ; \mathrm{P}<0.0001$, student's $t$-test), with predictable vessel anatomy, single IM vein in $81.4 \%$ versus $74 \%$ in the 2nd and 3rd ICSs respectively, evidence that the venous confluence had predominantly occurred by the $3 \mathrm{rd}$ rib and thus the vein in the 2 nd space is of larger calibre than its 3rd space tributaries (2). Taking into account the above we contend that pre-operative assessment of IMVs using CT scan is superfluous especially since not all breast cancers 


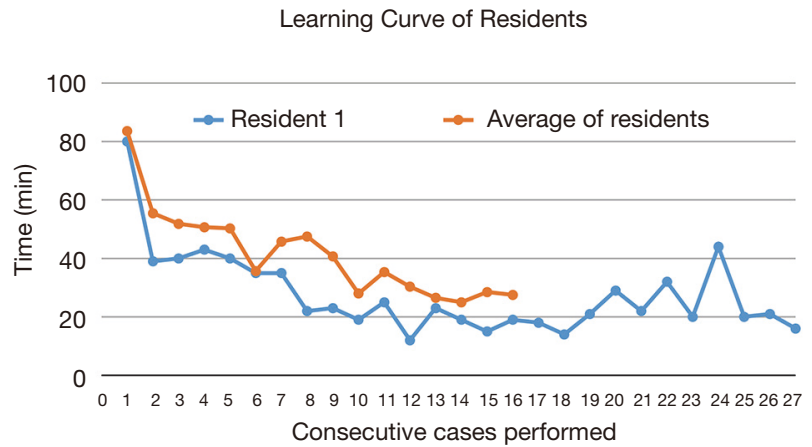

Figure 1 Learning curve of 11 residents illustrated by the time taken for rib-preserving IMV exposure in consecutive cases. IMV, internal mammary vessel.

undergoing mastectomy need staging chest CTs. Such routine $\mathrm{CTs}$ expose the patient to unnecessary radiation in addition to that from CT angiography for mapping the abdominal wall perforators.

We also maintain that total rib preserving IMV exposure is easy to learn and the time taken for IMV dissection plateaues off after about 7 consecutive cases for surgeons new to the technique. This is amply illustrated by multiple rotating residents in our Unit, especially highlighted by one resident who performed 25 consecutive cases with a median time of only 22 minutes (Figure 1) (2). Other residents had similar early curves as shown when interposed with the longest serving trainee. These findings are in agreement with Zhang et al.'s suggestion that this technique can be easily learned (although no evidence to support this is proffered) and readily adopted into existing microsurgical practices. After a few cases the trainees are able to safely undertake rib-preserving IMV exposure in less than 25 minutes similar to rib sacrifice performed by the most experienced surgeons (8).

Furthermore, we have refined the rib-preserving IMV exposure and extended it to dissecting both the $2 \mathrm{nd}$ and $3 \mathrm{rd}$ intercostal spaces without sacrificing the intervening costal cartilage (9). Indications for this include bipedicled DIEP and DIEP/SIEA flaps, stacked DIEP flaps and for salvage procedures allowing multiple anterograde and retrograde microvascular anastomoses without complication $(9,10)$.

In conclusion we advocate rib-preserving IMV exposure as a safe, reproducible technique, with a short learning curve and a consistent topographic anatomy especially when utilising the 2 nd intercostal space. It can be used for either a single space or for simultaneous exposure of the IMVs in contiguous spaces when multiple anastomoses are indicated. Our practice does not involve pre-operative CT scan of the IMVs as it is almost always unnecessary and we have consecutively performed this technique without any major complication and an overall flap success rate of $99.7 \%$. Zhang et al.'s study confirms our previous reports.

\section{Acknowledgments}

Funding: None.

\section{Footnote}

Conflicts of Interest: All authors have completed the ICMJE uniform disclosure form (available at http://dx.doi. org/10.21037/gs.2019.12.21). The authors have no conflicts of interest to declare.

Ethical Statement: The authors are accountable for all aspects of the work in ensuring that questions related to the accuracy or integrity of any part of the work are appropriately investigated and resolved.

Open Access Statement: This is an Open Access article distributed in accordance with the Creative Commons Attribution-NonCommercial-NoDerivs 4.0 International License (CC BY-NC-ND 4.0), which permits the noncommercial replication and distribution of the article with the strict proviso that no changes or edits are made and the original work is properly cited (including links to both the formal publication through the relevant DOI and the license). See: https://creativecommons.org/licenses/by-nc-nd/4.0/.

\section{References}

1. Zhang Q, Xiao Q, Guo R, et al. Applications of rib sparing technique in internal mammary vessels exposure of abdominal free flap breast reconstructions: a 12year single-center experience of 215 cases. Gland Surg 2019;8:477-85.

2. Sasaki Y, Madada-Nyakauru R, Samaras S, et al. The ideal intercostal space for internal mammary vessel exposure during total rib-sparing microvascular breast reconstruction: A critical evaluation. J Plast Reconstr Aesthet Surg 2019;72:1000-6.

3. Malata CM, Moses M, Mickute Z, et al. Tips for successful microvascular abdominal flap breast reconstruction utilizing the "total rib preservation" technique for internal mammary vessel exposure. Ann Plast Surg 2011;66:36-42.

4. Rosich-Medina A, Bouloumpasis S, Di Candia M, et al. 
Total "rib"-preservation technique of internal mammary vessel exposure for free flap breast reconstruction: A 5-year prospective cohort study and instructional video. Ann Med Surg (Lond) 2015;4:293-300.

5. Parrett BM, Caterson SA, Tobias AM, et al. The ribsparing technique for internal mammary vessel exposure in microsurgical breast reconstruction. Ann Plast Surg 2008;60:241-3.

6. Khoo A, Rosich-Medina A, Woodham A, et al. The relationship between the intercostal distance, patient height and outcome in microsurgical breast reconstruction using the second interspace rib-sparing internal mammary vessel exposure. Microsurgery 2014;34:448-53.

7. Mickute Z, Di Candia M, Moses M, et al. Analgesia requirements in patients undergoing DIEP flap breast

Cite this article as: Samaras S, Sasaki Y, Malata C. Letter to the editor: applications of rib sparing technique in internal mammary vessels exposure of abdominal free flap breast reconstructions: a 12-year single-center experience of 215 cases. Gland Surg 2020;9(2):498-500. doi: 10.21037/gs.2019.12.21 reconstructions: Rib preservation versus rib sacrifice. J Plast Reconstr Aesthet Surg 2010;63:e837-9.

8. Malata C, Sasaki Y, Oni G. Five steps to internal mammary vessel preparation in less than 15 minutes. Plast Reconstr Surg 2018;142:581e-582e.

9. Oni G, Malata CM. New surgical technique - simultaneous use of contiguous intercostal spaces during total-rib preservation exposure of the internal mammary vessels in microvascular breast reconstruction. J Plast Reconstr Aesthet Surg 2019;72:1525-9.

10. Malata CM, Rabey NG. Decision Making in DoublePedicled DIEP and SIEA Abdominal Free Flap Breast Reconstructions: An Algorithmic Approach and Comprehensive Classification. Front Surg 2015;2:49. 